\title{
Study on straightness deviation control in the BTA deep hole drilling based on thermal-mechanical coupling simulation method
}

\author{
Xiaohua ZHU*, Rui ZHANG*, Tian LI**, Liangliang DONG* and Yuan TANG* \\ * School of Mechatronic Engineering, Southwest Petroleum University \\ Chengdu, Sichuan 610500, PR China \\ E-mail: zhuxh@swpu.edu.cn \\ ** Air China Aviation Technology Co., LTD. \\ Chengdu, Sichuan 610041, PR China
}

Received: 16 April 2021; Revised: 7 July 2021; Accepted: 3 August 2021

\begin{abstract}
Nickel-based superalloys also have super high strength at high temperatures, which are typically difficult to be processed. As the material of hydraulic parts, aircraft engines, and downhole intelligent tools, it has the characteristics of large cutting deformation, severe work hardening, and low thermal conductivity in deep hole machining, which will lead to the problem of poor straightness of the deep hole. In order to solve the problem of poor straightness of the deep hole in machining nickel-based superalloys, a three-dimensional finite element model of BTA deep hole drilling based on thermal-mechanical coupling is established, and the influence of different blade angles, rotation speeds, and feed rates on drilling force is calculated. The prediction model of drilling force is obtained based on the response surface regression analysis method, and the multi-objective optimization of blade angle, rotation speed, and feed rate are carried out by using the random direction search method. The BTA deep hole drilling experiments are carried out by using the optimized tool and process parameters, and the effects of different process parameters on the straightness of the deep hole of nickel-based superalloys are analyzed. The results of the research show that: Different rotation speeds and feed rates will lead to different degrees of strain hardening and thermal softening. This will lead to a significant difference in the value of the drilling force on the tool. The straightness deviation of the deep hole in nickel-based superalloys can be controlled by optimizing the tool structure and process parameters. The research work in this paper can provide a basis for the structural design of the BTA tool and optimization of process parameters.
\end{abstract}

Keywords : Thermal-mechanical coupling, Straightness deviation control, Multi-objective optimization , Nickelbased superalloy, Numerical simulation

\section{Introduction}

Nickel-based superalloys also have super high strength at high temperatures (Ohashi et al., 2012), which are typically difficult to be processed (Lu et al., 2019), and have been widely used in aerospace and petroleum industries. The material contains $\mathrm{Mo}, \mathrm{Ti}, \mathrm{Ni}, \mathrm{Nb}, \mathrm{Cr}$, and other elements with stable atomic structure, which has a high melting point and high activation energy, resulting in poor relative machinability (Attanasio et al., 2020). As the material of hydraulic parts, aircraft engines, and downhole intelligent tools, it has the characteristics of large cutting deformation, severe work hardening, and low thermal conductivity in deep hole machining (Paturi et al., 2021), which will lead to problems of poor straightness of deep hole and low qualified rate (Ahmed et al., 2019). These parts are expensive. If the deep hole straightness of the nickel-based superalloys is unqualified, it will cause a scrap of the workpiece, increase the cost and reduce the production efficiency. The boring and trepanning association (BTA) deep hole drilling is widely used in high length-to-diameter ratio and high precision deep hole machining in the field of aerospace and petroleum industries (Li et al., 2018). Therefore, the research focus of this paper is to improve the straightness of the deep hole about BTA drilling 
nickel-based superalloys. In order to improve the straightness of the deep hole, many scholars have done a lot of research work, mainly from the following three aspects.

In the area of theoretical research on the deflection of hole axes, Ahmadi et al. (Ahmadi and Altintas, 2013) proposed a general drilling dynamic model to deal with the problem of hole axis deflection caused by the lateral, axial, and torsional deflections during the drilling process. Woon et al. (Woon et al., 2014) proposed a dynamic model that considers force, bit deflection, and hole wall deformation, and pointed out that the edge radius of the gun drill would have an effect on the deflection of the hole axis. Ma et al. (Ma and Shen, 2018) proposed the lateral vibration control equation of the drilling system, and pointed out that appropriate rotation angular velocity and support constraints can improve the stability of the system. Li et al. (Li et al., 2020) proposed a prediction model of hole straightness deviation in the process of multi-support deep hole drilling. Lew et al. (Lew et al., 2020) established a multi-span rotational dynamic model under the action of thrust and coolant pressure, and obtained the coolant pressure and rotation speed when the straightness of the hole was better.

In the study of the factors affecting the straightness of holes, Woon et al. (Woon et al., 2014) pointed out that the wear rate on the inner and outer blade is different, which will reduce the self-conducting performance of the drill. Finally, the hole will produce axis deflection with a constant trend. Malarvizhi et al. (Malarvizhi et al., 2016) pointed out that the structure of the offset tool can easily tilt the tip of the tool toward the bearing pad, resulting in the deviation of the hole axis. Based on this, a method of controlling the deformation of the bearing bush is proposed to improve the deflection of the hole axis. Liu et al. (Liu et al., 2018) pointed out that tool wear during drilling will cause the change of force balance. Eventually, the machining axis will deviate from the correct axis of the hole. Khadtare et al. (Khadtare et al., 2020) pointed out that reasonable feed rate and rotation speed will improve the service life of the tool, it is proved by experiments that the increase of tool life is beneficial to the improvement of straightness of deep hole. Neo et al. (Neo et al., 2020) developed a polycrystalline cubic boron nitride (PCBN) gun drill to solve the problem of poor hole straightness caused by tool degradation. Compared with traditional carbide gun drills, the PCBN gun drill can not only reduce drilling force and tool wear but also improve hole straightness.

In the research of straightness deviation control methods, Matsuzaki et al. (Matsuzaki et al., 2015) designed a new tool that can suppress chattering to improve the straightness of the deep hole. Biermann et al. (Biermann and iovkov, 2015) Pointed out that the tapered guide chamfer of the single-lip gun drill would cause the straightness deviation, based on which they proposed a radial spindle compensation method and experimentally demonstrated the effectiveness of the method. Zhang et al. (Zhang et al., 2018) designed a customized tool regrinding system that makes it possible to obtain high-quality tools with precisely controlled geometry to improve the straightness of the deep hole. Ahmed et al. (Ahmed et al., 2019) proposed a novel EDMG method for deep hole machining. Experimental studies have found that this EDMG process can reduce the straightness deviation. Gerken et al. (Gerken et al., 2020) developed a compensation device to correct the straightness deviation by changing the target inclination of the drill bit, and investigated the effect of the compensation unit on the straightness deviation by means of finite element analysis.

To sum up, many scholars have conducted researches on the axis deflection theory, factors influencing hole straightness, and the control method of hole straightness. However, from the perspective of establishing a threedimensional finite element model of BTA deep hole drilling based on thermal-mechanical coupling, the research on the straightness deviation control of the deep hole in nickel-based superalloys by optimizing the tool structure and process parameters is rarely mentioned. Based on the thermal-mechanical coupling theory, theory of friction in metal cutting, and Johnson-Cook plastic constitutive model, a three-dimensional finite element model of BTA deep hole drilling is established, and the effects of different blade angles, rotation speeds, and feed rates on drilling force are calculated. the multi-objective optimization of blade angle, rotation speed, and feed rate are carried out by using the random direction search method. The BTA deep hole drilling experiments are carried out by using the optimized tool and process parameters, and the effects of different process parameters on the straightness of the deep hole of Nickel-based superalloys are analyzed.

\section{Simulation of deep hole drilling in nickel-based superalloys}

The heat generated during the process of metal cutting is mainly converted from the plastic deformation of metal and the friction between the tool surface and the metal surface. Therefore, this section elaborates the heat-force relationship in the process of BTA drilling nickel-based superalloys from the perspective of thermal-mechanical coupling theory and 
theory of friction in metal cutting. The Johnson-Cook constitutive equation suitable for drilling nickel-based superalloys is used to establish the finite element simulation calculation model.

\subsection{Thermal-mechanical coupling equation}

The heat transfer during the metal cutting process belongs to the phenomenon of transient heat transfer containing inner heat source. The plastic function transformation in the process of plastic deformation can be regarded as the inner heat source, and the thermal conduction of metal materials is isotropic. Based on the law of conservation of energy and Fourier's law, a three-dimensional differential equation of heat conduction is established. The governing equation is as follows (Furukawa and Moronuki, 1988):

$$
\lambda\left[\frac{\partial^{2} T}{\partial^{2} x^{2}}+\frac{\partial^{2} T}{\partial^{2} y^{2}}+\frac{\partial^{2} T}{\partial^{2} z^{2}}\right]-\rho c\left[u \frac{\partial T}{\partial x}+v \frac{\partial T}{\partial y}+\omega \frac{\partial T}{\partial z}\right]+\frac{M W_{h} \dot{W}_{p}}{\rho}=0
$$

Where: $\lambda$-the thermal conductivity; $\rho$-the density of the material; $c$ - the specific heat capacity of the material; $M$ - the mechanical equivalent of heat; $W_{h}$-the ratio of plastic work to heat energy; $\dot{W}_{p}$-plastic strain rate; $x 、 y 、 z \quad$ cartesian coordinates; $u 、 v 、 \omega$-the velocity components of heat source in $x, y$, and z directions.

In order to obtain the solution of the thermal equilibrium equation, boundary conditions and initial conditions need to be defined and solved simultaneously. The basic finite element equation of thermal problem can be expressed as $(\mathrm{Hu}$ et al., 2000):

$$
\begin{aligned}
& C \dot{T}+K_{T} T=Q \\
& C=\int \rho(T) c(T) N N^{T} d_{V} \\
& K_{T}=\int \lambda(T) B B^{T} d_{V}
\end{aligned}
$$

Where: $\mathcal{C}$-specific heat capacity matrix; $K_{T}$-heat conduction matrix; $N$-shape function matrix; $B$-geometric matrix; $T$-node temperature vector; $\dot{T}$-node temperature change rate vector; $Q$-heat flux vector.

In the calculation of thermal-mechanical coupling in the drilling process, the basic equation of thermal-mechanical coupling considering deformation, friction, temperature change, and thermal expansion is as follows:

$$
\left[\begin{array}{ll}
0 & 0 \\
0 & c
\end{array}\right]\left[\begin{array}{c}
\dot{u} \\
\dot{T}
\end{array}\right]+\left[\begin{array}{cc}
k & 0 \\
0 & k
\end{array}\right]\left[\begin{array}{l}
u \\
T
\end{array}\right]=\left[\begin{array}{l}
F \\
Q
\end{array}\right]
$$

Where: $u$-nodal displacement vector; $\dot{u}$-nodal velocity vector; $F$-force vector, including the applied nodal force vector and the force caused by thermal strain.

\subsection{Theory of friction in metal cutting}

In the process of metal cutting, the stress distribution on the rake face is uneven. The friction between chip and rake face can be divided into adhesive friction region and sliding friction region. The region of adhesive friction can be considered as internal friction, where friction is intense. The area between the rake face and the chip is high temperature and high pressure. The normal stress is the largest at the edge of blade. Until the chip is separated from the rake face, the normal stress decreases to 0 . In the adhesive friction region, the unit friction shear stress is equal to the shear yield stress of the workpiece material. In the sliding friction region, the unit friction shear stress gradually decreases to 0 . The above friction relationship can be expressed as: 


$$
\begin{cases}\tau_{f}=\tau_{p}, \mu \sigma_{n} \geq \tau_{p} & \text { (adhesive friction region }) \\ \tau_{f}=\mu \sigma_{n}, \mu \sigma_{n} \leq \tau_{\mathrm{p}} & (\text { sliding friction region })\end{cases}
$$

Where: $\tau_{f}$-friction shear stress; $\tau_{p}$-shear yield stress of workpiece material; $\sigma_{n}$ - normal stress between rake face and cutting contact surface; $\mu$-friction factor.

\subsection{Theory of friction in metal cutting}

In this paper, the finite element method is used to simulate BTA deep hole drilling nickel-based superalloys. The workpiece material studied in this paper is Inconel 718, which is a large strain rate non-ferrous metal. The Johnson-Cook (JC) constitutive model is very suitable for simulating the stress-strain relationship of ferrous and non-ferrous metals with large strain rates, especially for simulating the effects of strain hardening, strain rate strengthening, and thermal softening in the process of drilling nickel-based superalloys. Therefore, the J-C constitutive model is used to describe the plastic behavior of Inconel718. The J-C constitutive equation can be expressed as:

$$
\sigma=\left[A+B\left(\varepsilon^{p l}\right)^{n}\right]\left[1+C \ln \left(\frac{\varepsilon^{\cdot p l}}{\varepsilon_{o}^{\cdot}}\right)\right]\left[1-\left(\frac{T-T_{0}}{T_{m}-T_{0}}\right)^{m}\right]
$$

where: $\sigma$ - the yield stress at nonzero strain rate; $\varepsilon^{p l}$-the equivalent plastic strain; $\varepsilon^{\cdot p l}$-the equivalent plastic strain rate; $\varepsilon_{0}{ }^{-}$- the strain rate parameter, take the static strain rate as $1.0 / \mathrm{s} ; T$-the material temperature; $T_{0}$-the transition temperature; $T_{m}$-the melting temperature of the material. The Johnson-Cook plastic behavior constitutive parameters used in this paper are shown in Table 1(Uhlmann et al., 2007; Yu et al., 2010).

$\mathrm{J}-\mathrm{C}$ fracture failure model is adopted in the process of chip formation, and the definition of failure parameters is shown in Eq. (8). When the cumulative value of $w$ exceeds 1, it indicates that the material has fractured. At this point, the element stiffness is set to 0 , and the element is deleted.

$$
w=\sum\left(\frac{\Delta \bar{\varepsilon}^{p l}}{{\overline{\varepsilon_{f}}}^{p l}}\right)
$$

Where: $w$-fracture criterion measurement parameters of J-C model; $\Delta \bar{\varepsilon}^{p l}$-an increment of equivalent plastic strain; $\bar{\varepsilon}_{f}{ }^{p l}$ - the equivalent failure plastic strain.

$$
{\overline{\varepsilon_{f}}}^{p l}=\left[d_{1}+d_{2} \exp \left(d_{3} \frac{p}{q}\right)\right]\left[1+d_{4} \ln \left(\frac{\bar{\varepsilon}^{p l}}{\varepsilon_{0} \cdot}\right)\right]\left[1+d_{5} \mathrm{~T}^{*}\right]
$$

Where: ${\overline{\varepsilon_{f}}}^{p l}$ - the equivalent failure plastic strain; $p / q$ - the dimensionless pressure-deviatoric stress ratio; ( $p$ - the pressure stress, $q$ - the Mises stress); $\left(d_{1} \sim d_{5}\right)$ - the failure parameter measured at or below the transition temperature; $\mathrm{T}^{*}$ - the dimensionless temperature parameter.

Table 1 Johnson-Cook parameters of Inconel 718

\begin{tabular}{c|c|c|c|c|c}
\hline $\mathrm{A}\left(\mathrm{MP}_{\mathrm{a}}\right)$ & $\mathrm{B}\left(\mathrm{MP}_{\mathrm{a}}\right)$ & $n$ & $\mathcal{C}$ & $m$ & $\varepsilon_{0}$ \\
\hline 450 & 1700 & 0.65 & 0.017 & 1.3 & 1 \\
\hline
\end{tabular}




\subsection{Deep hole drilling model and boundary conditions}

In this section, based on the thermal-mechanical coupling equation, theory of friction in metal cutting, and J-C constitutive model, a simulation calculation model of BTA deep hole drilling Inconel 718 is established with finite element simulation software.

\subsubsection{Geometric model and mesh}

The tool structure is appropriately simplified in the modeling process. local structures such as drill thread, guide bar chamfer, and non-cutting area of the blade are omitted. The mesh element type of the workpiece adopts C3D8R (Fig. 1 (c)). The mesh in the middle drilling area is encrypted, and the mesh in other areas is sparse. This method can not only reduce the total number of mesh elements, but also achieve the required calculation accuracy and improve the calculation efficiency. The mesh element type of the blade adopts C3D8R. The mesh element type of the drill handle adopts C3D10MT. All meshes are coupled by temperature-displacement. The mesh division of the drilling model, tool structure, and drilling region are shown in Fig. 1. The main geometric parameters of the tool are shown in Table 2.

Table 2 The main geometric parameters of the tool

\begin{tabular}{c|c|c|c|c|c|c}
\hline \hline Rake angle & $\begin{array}{c}\text { Relief angle of } \\
\text { the outer blade }\end{array}$ & $\begin{array}{c}\text { Relief angle of the } \\
\text { intermediate blade }\end{array}$ & $\begin{array}{c}\text { Relief angle } \\
\text { of the center } \\
\text { blade }\end{array}$ & $\begin{array}{c}\text { Deflection } \\
\text { angle of the } \\
\text { outer blade }\end{array}$ & $\begin{array}{c}\text { Deflection } \\
\text { angle of the } \\
\text { inner blade }\end{array}$ & $\begin{array}{c}\text { Tool } \\
\text { diameter }\end{array}$ \\
\hline $0^{\circ}$ & $8^{\circ}$ & $8^{\circ}$ & $12^{\circ}$ & $13^{\circ}$ & $18^{\circ}$ & $63.5 \mathrm{~mm}$ \\
\hline
\end{tabular}

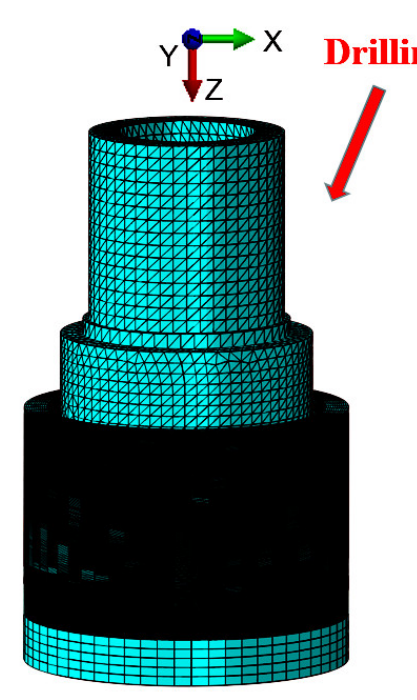

(a)

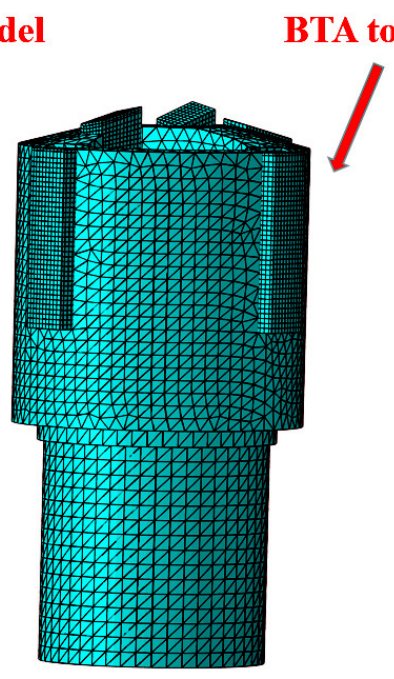

(b)

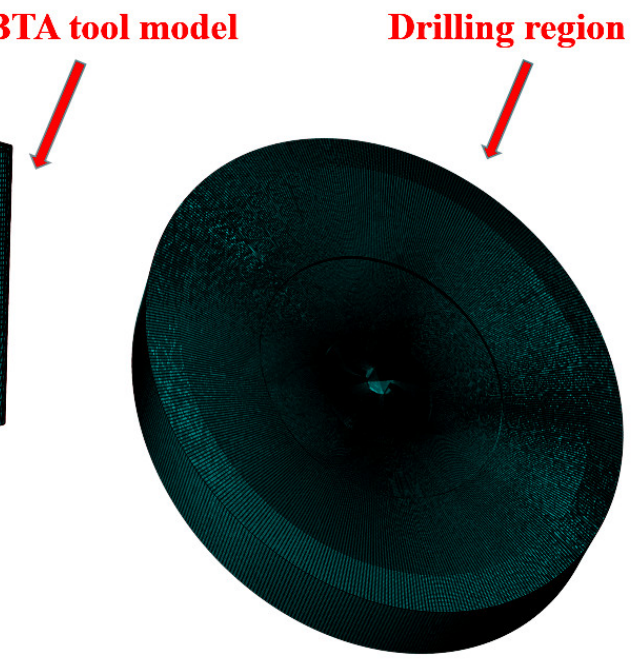

(c)

Fig. 1 Mesh division

\subsubsection{Physical properties of the material}

The workpiece material is Inconel718, the blade material of the BTA tool is cemented carbide WC, and the drill handle material is AISI-1045 steel. The physical properties of the material are shown in Table 3.

Table 3 Physical properties

\begin{tabular}{|c|c|c|c|}
\hline Material properties & Inconel 718 & $\mathrm{WC}$ & AISI-1045 Steel \\
\hline Young's modulus(Pa) & $2.06 \times 10^{11}$ & $6 \times 10^{11}$ & $2.09 \times 10^{11}$ \\
\hline Poisson's ratio & 0.3 & 0.26 & 0.269 \\
\hline Density $\left(\mathrm{kg} \cdot\left(\mathrm{m}^{3}\right)^{-1}\right)$ & 8200 & 15000 & 7850 \\
\hline Specific heat $\left(\mathrm{J} \cdot(\mathrm{kg} \cdot \mathrm{K})^{-1}\right)$ & 435 & 512 & 465 \\
\hline Thermal conductivity $\left(\mathrm{W} \cdot(\mathrm{m} \cdot \mathrm{K})^{-1}\right)$ & 11.4 & 79.6 & 47.68 \\
\hline $\begin{array}{l}\text { Coefficient of linear thermal } \\
\text { expansion }\left(\mathrm{mm} \cdot(\mathrm{mm} \cdot \mathrm{K})^{-1}\right)\end{array}$ & $1.18 \times 10^{-5}$ & $4.9 \times 10^{-6}$ & $1.159 \times 10^{-5}$ \\
\hline
\end{tabular}




\subsubsection{Boundary conditions}

The workpiece material is the deformable body, and the bottom of the workpiece is fully constrained. The tool is set as a rigid body, and the reference point of the BTA tool is set at the axis point of the tail end of the drill handle. Rigidbody coupling constraint is carried out between the BTA tool and the reference point. The rotation speed amplitude curve is applied to the reference point. The drilling process adopts an explicit dynamic nonlinear analysis step.

\section{Simulation results and analysis}

The thermal-mechanical coupled elastoplastic finite element method based on the finite strain theory is one of the most effective methods for studying and solving metal cutting problems. In this section, finite element software is used to study the influence of different rotation speeds, feed rates, and blade angles on the drilling force, which provides the basis for the optimization of the tool structure and process parameters.

\subsection{Analysis of the drilling process}

Figure 2 shows the process of the BTA tool completing a circle of drilling the workpiece. The BTA tool drills at a specified rotation speed and feed rate in the axial direction. As the tool continues to rotate and feed, large elastic-plastic deformation of the workpiece material occurs under the action of the three blades, and the cutting process gradually changes from extrusion deformation to shear damage, the mesh unit is deleted and the stiffness becomes zero.

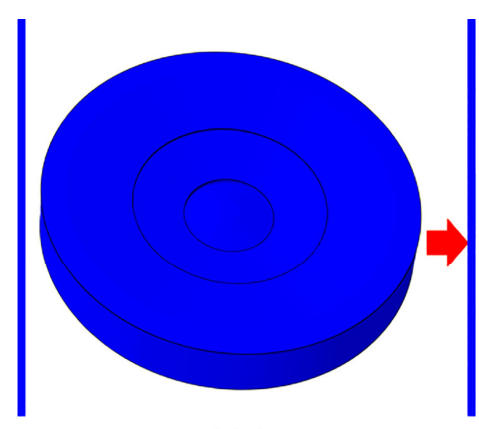

(a) $0 \mathrm{~s}$

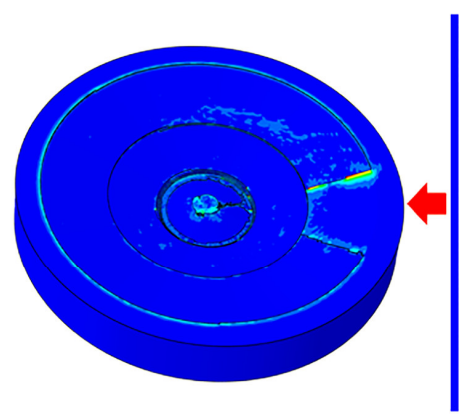

(f) $0.31 \mathrm{~s}$

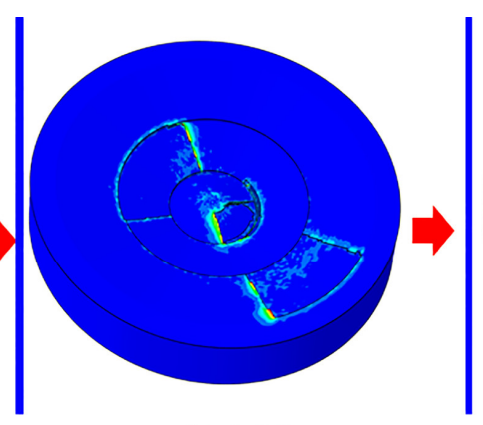

(b) $0.077 \mathrm{~s}$

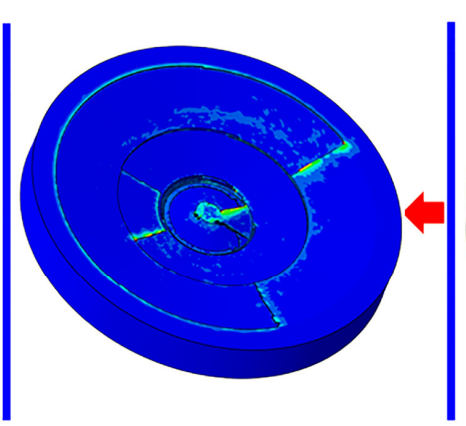

(e) $0.256 \mathrm{~s}$

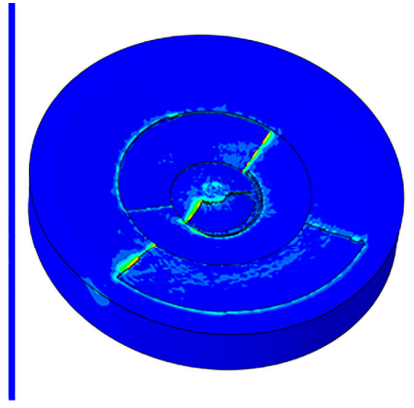

(c) $0.124 \mathrm{~s}$

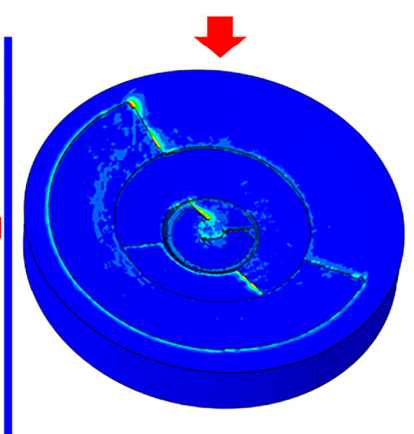

(d) $0.217 \mathrm{~s}$

Fig. 2 The BTA tool completes a circle of drilling the workpiece

\subsection{Extraction and processing of drilling force}

The machining process parameters are substituted into the simulation calculation model and the drilling process is shown in Fig. 2. Furthermore, Fig. 3 shows the outer blade path of the tool, from which you can see the entire tool rotation and feed process. As the Cartesian coordinate system is used to extract the data of drilling forces in this paper, the forces obtained on the $\mathrm{X}$ and $\mathrm{Y}$ axes show a sine and cosine function distribution. The combined force vectors in the $\mathrm{X}$ and $\mathrm{Y}$ axis directions are summed and then redistributed in the radial and tangential directions of the hole to obtain the tangential and radial forces during drilling. At special angles, such as when the blade is exactly in the X-axis, this time the radial force coincides with the Y-axial force and the tangential force coincides with the X-axial force when the Y-axial force is at its maximum, but at this time the X-axial force is not at its maximum, as shown in Fig. 4. 


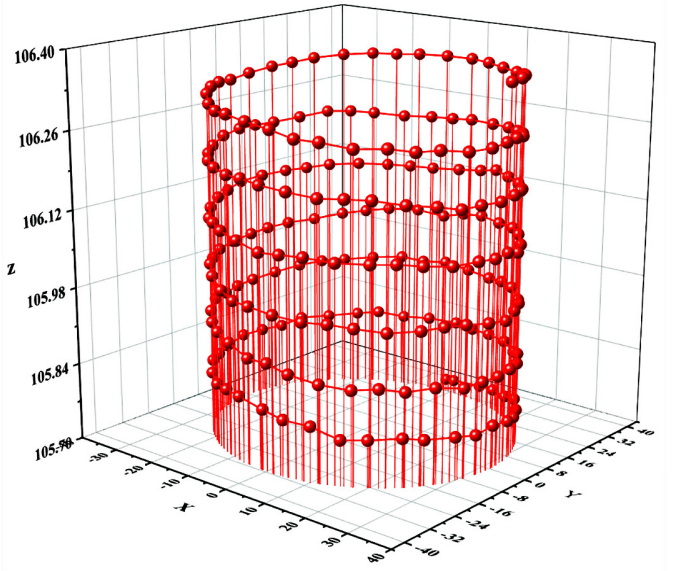

Fig. 3 The path of the outer blade of BTA tool

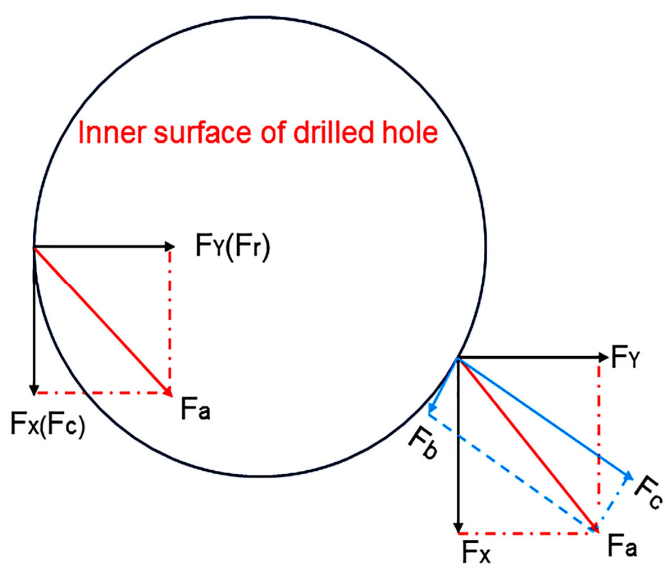

Fig.4 Analysis of force direction on the inner surface of the drilled hole

\subsection{The influence of feed rate and rotation speed on drilling force}

In this paper, the cutting force $\left(\mathrm{F}_{\mathrm{C}}\right)$ in the $\mathrm{X}$-axis direction and the axial force $(\mathrm{Fa})$ in the $\mathrm{Z}$-axis direction are selected as the research and analysis objects (Haddag et al., 2020). Since the cutting forces in the X-axis and Y-axis direction are all in the rule of sine and cosine, the force in the $\mathrm{X}$-axis is sufficiently representative (Li et al., 2020). For the convenience of explanation, the maximum force in $\mathrm{X}$-axis direction is collectively referred to as the cutting force $\left(\mathrm{F}_{\mathrm{C}}\right)$ in this study.

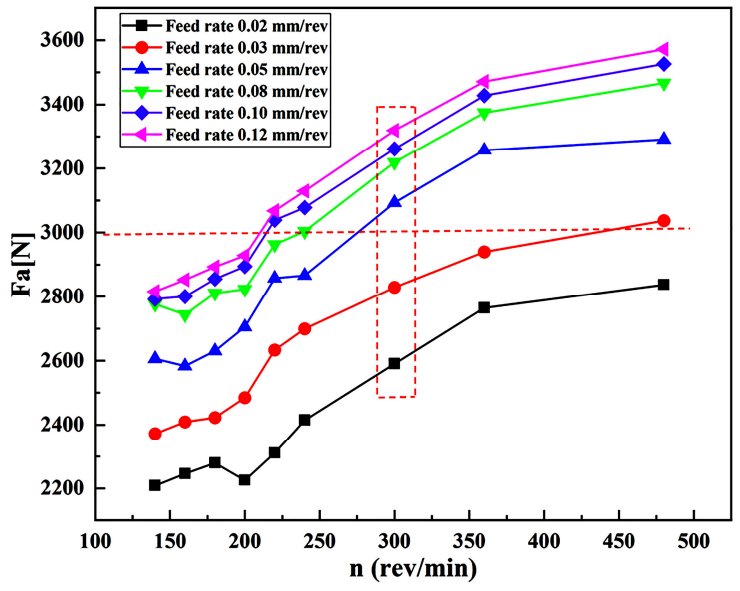

(a) The influence of rotation speed on axial force

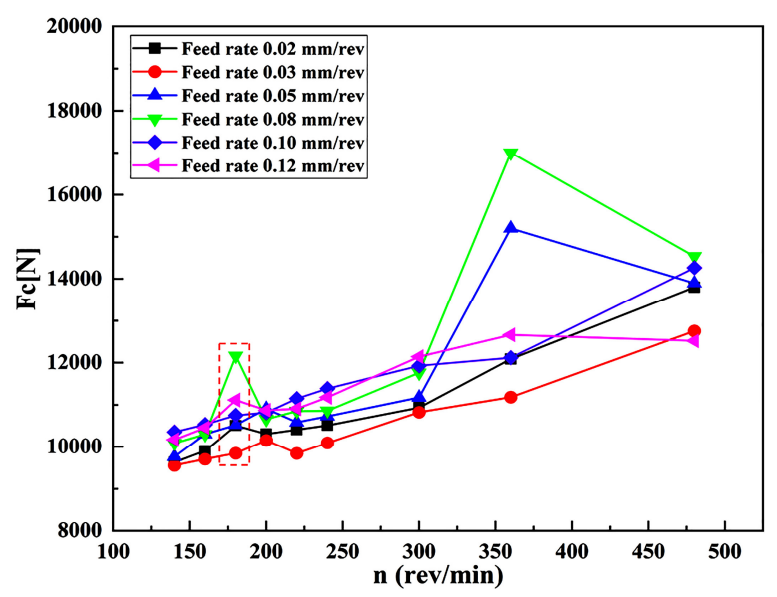

(c) The influence of rotation speed on cutting force

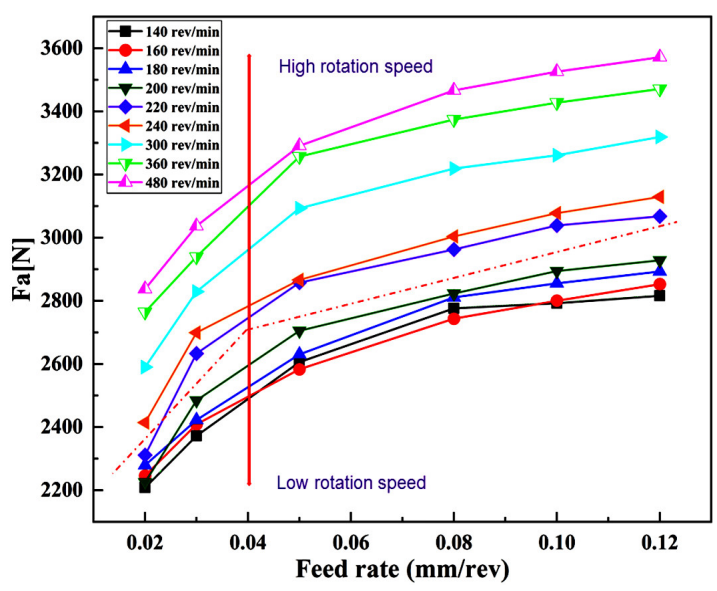

(b) The influence of feed rate on axial force

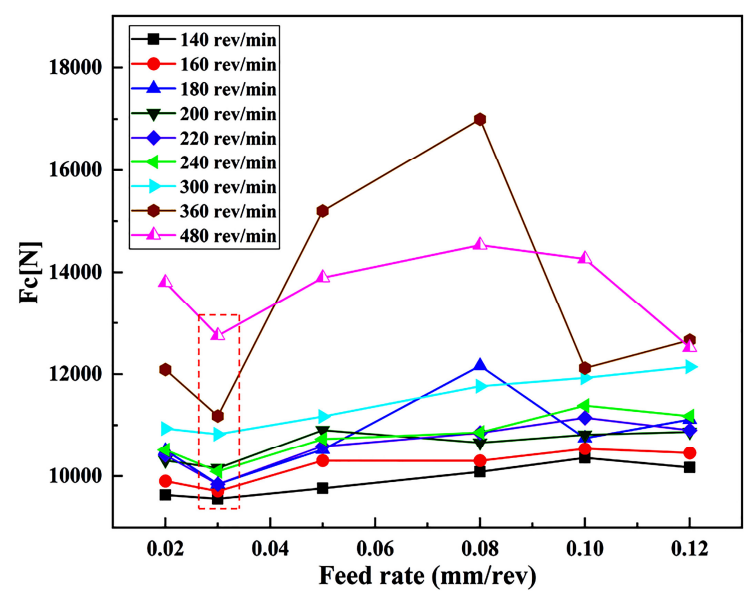

(d) The influence of feed rate on cutting force

Fig. 5 The influence of feed rate and rotation speed on drilling force 
Figure 5 shows the influence of feed rate and rotation speed on the drilling force. As can be seen from Fig. 5(a) and Fig. 5(b), the amplitude of the axial force (Fa) shows an upward trend as the rotation speed and feed rate increase. In the low rotation speed range (140-220 rev/min), under the same feed rate, the axial force increases slightly with the increase of rotation speed. There is not much difference in amplitude. In the high rotation speed range (240-480 rev/min), under the same feed rate, the higher the rotation speed, the greater the axial force. The difference in the magnitude of the axial force $(\mathrm{Fa})$ can reach $1000 \mathrm{~N}$. As can be seen from Fig. $5(\mathrm{c})$, when the feed rate is $0.03 \mathrm{~mm} / \mathrm{rev}$, the cutting force $\left(\mathrm{F}_{\mathrm{C}}\right)$ on the tool is the minimum. the smaller the cutting force, which means that the less likely the edge of the outer blade will break. it also means that the tendency of the blade expanding from the inside to the outside in the radius direction of the deep hole is less pronounced. Correspondingly, the higher the possibility of the BTA tool drilling along the specified path, the better the straightness of the deep hole. At this time, the possibility of tool wear and fracture is smaller.

When the rotation speed is $180 \mathrm{rev} / \mathrm{min}$, the cutting force is larger than the adjacent rotation speed. It shows that the erosion of the hole wall in the radial direction is more obvious and the tool is easy to wear at this rotation speed. When the rotation speed is $360 \mathrm{rev} / \mathrm{min}$ and the feed rate is greater than $0.05 \mathrm{~mm} / \mathrm{rev}$, the value of $\mathrm{F}_{\mathrm{C}}$ increases sharply. This means that the material of Inconel 718 has a significant hardening phenomenon under this condition. It can be seen from Fig. 5(d) that the cutting force $\left(\mathrm{F}_{\mathrm{C}}\right)$ presents a wavy trend with the increase of feed rate when the rotation speed is constant. The cutting force amplitude shows an overall upward trend, which indicates that there is an optimal solution in a decreasing range of cutting force amplitude. The hardening and thermal softening of the material varies under different processing parameters. The more obvious the hardening phenomenon is, the higher the deformation resistance in the shear zone and $\mathrm{F}_{\mathrm{C}}$ value will be.

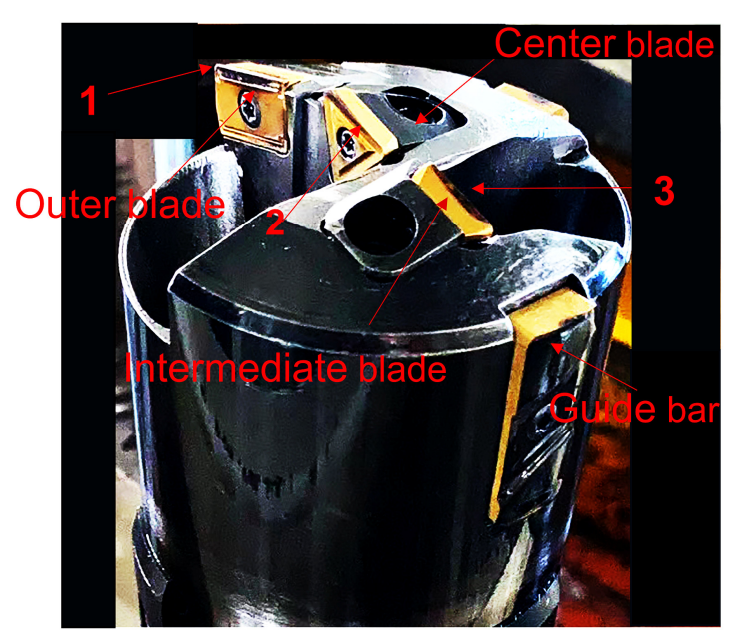

Fig. 6 The thermal damage of blade

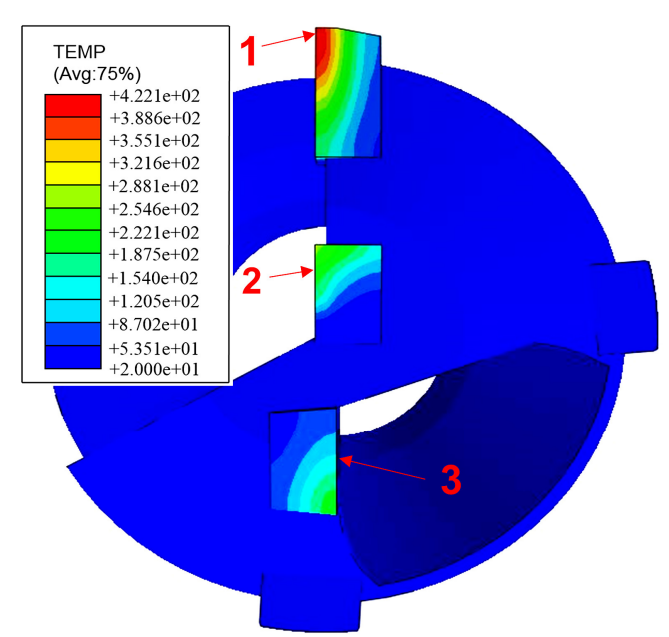

Fig. 7 Temperature field value at the moment when the BTA tool drills the workpiece for one circle

The thermal damage of the blade is shown in Fig. 6, and the temperature field of the blade is shown in Fig. 7. Compared with Fig. 6 and Fig. 7, it is obvious that the simulation results are in good agreement with the temperature field distribution of the tool in the factory (Fig. 6). From the three positions in Fig. 7, it can be seen that the temperature of the blade diffuses around the edge of the blade. The closer the edge of the blade is, the higher the temperature is. The position of the edge of the blade belongs to the adhesion region, which is in a high temperature and high-pressure environment. According to the theory of friction in metal cutting, this position is more prone to wear and break. the temperature value is the highest at the edge of the outer blade (position 1 in Fig. 7). This maintains a high degree of consistency with position 1 in Fig. 6 . The reason is that the linear velocity is the highest and the friction is the most intense at the edge of the outer blade. As known from the field drilling of Inconel 718, the edge of the outer blade (position 1 in Fig. 7) is also the most vulnerable to wear and break compared with other blade areas.

\subsection{The influence of blade angle on drilling force}

The tool structure has a significant impact on the quality of BTA deep hole drilling, and the blade angle is one of the most important factors. Therefore, in this paper, the rake angle of the blade, the relief angle of the outer blade and 
intermediate blade, and the relief angle of the center blade are selected as the key research factors. the single factor control variable method is used to study the influence of the change of the blade angle on the drilling force. Fig. 8 represents the effect of different angles of the blade on the axial force of the tool.

Fig. 8(a)、(b)、(c)、(d) adapt the same rotation speed and feed rate, rotation speed $200 \mathrm{rev} / \mathrm{min}$, feed rate 0.03 $\mathrm{mm} / \mathrm{rev}$. Fig. 8(a) shows the effect of the rake angle of the blade on the axial force when the relief angle is $10^{\circ}$. Furthermore, except for the change in the rake angle of the tool, the rest of the tool angle remains unchanged and the tool structure parameters in Table 2 are still used. Fig. 8(b) shows the effect of the rake angle of the blade on the axial force when the relief angle is $8^{\circ}$. Fig. 8(c) shows the effect of the relief angle of the center blade on the axial force. Fig. 8(d) shows the relief angle of the blade on the axial force when the rake angle is $0^{\circ}$.

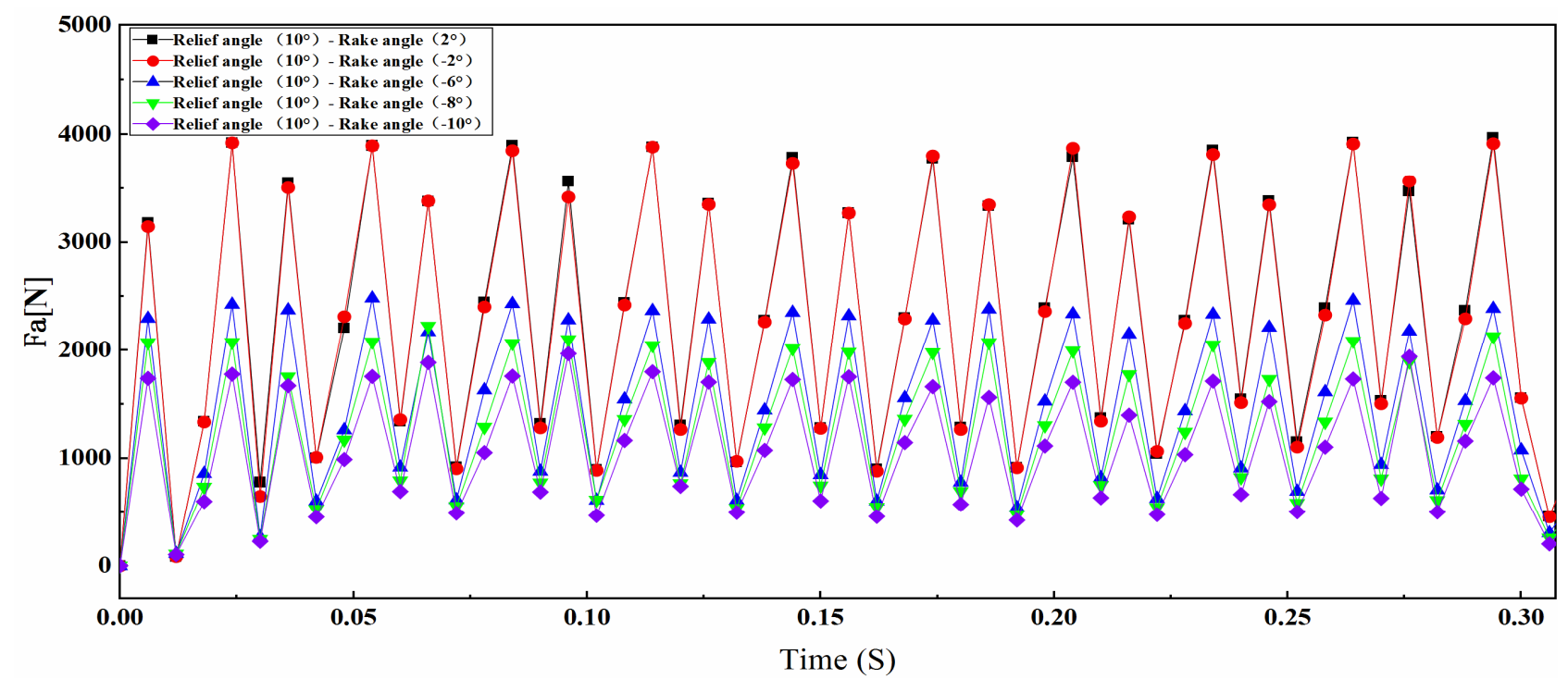

(a) The influence of rake angle of the blade on axial force

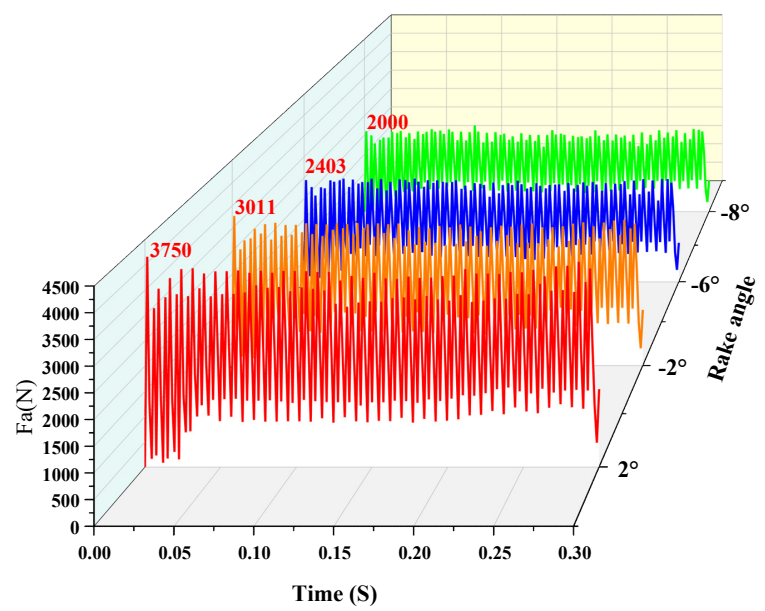

(b) The influence of rake angle of the blade on axial force

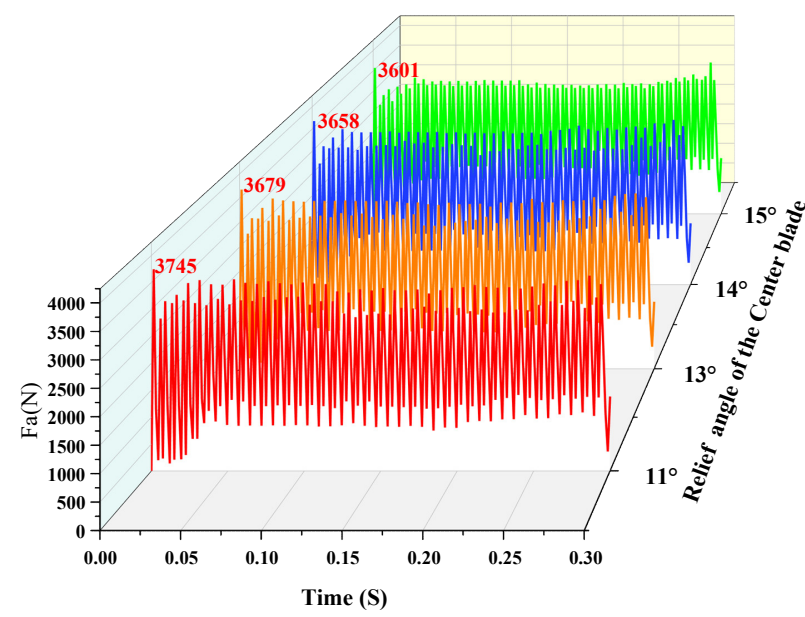

(c) The influence of relief angle of the center blade on axial force 


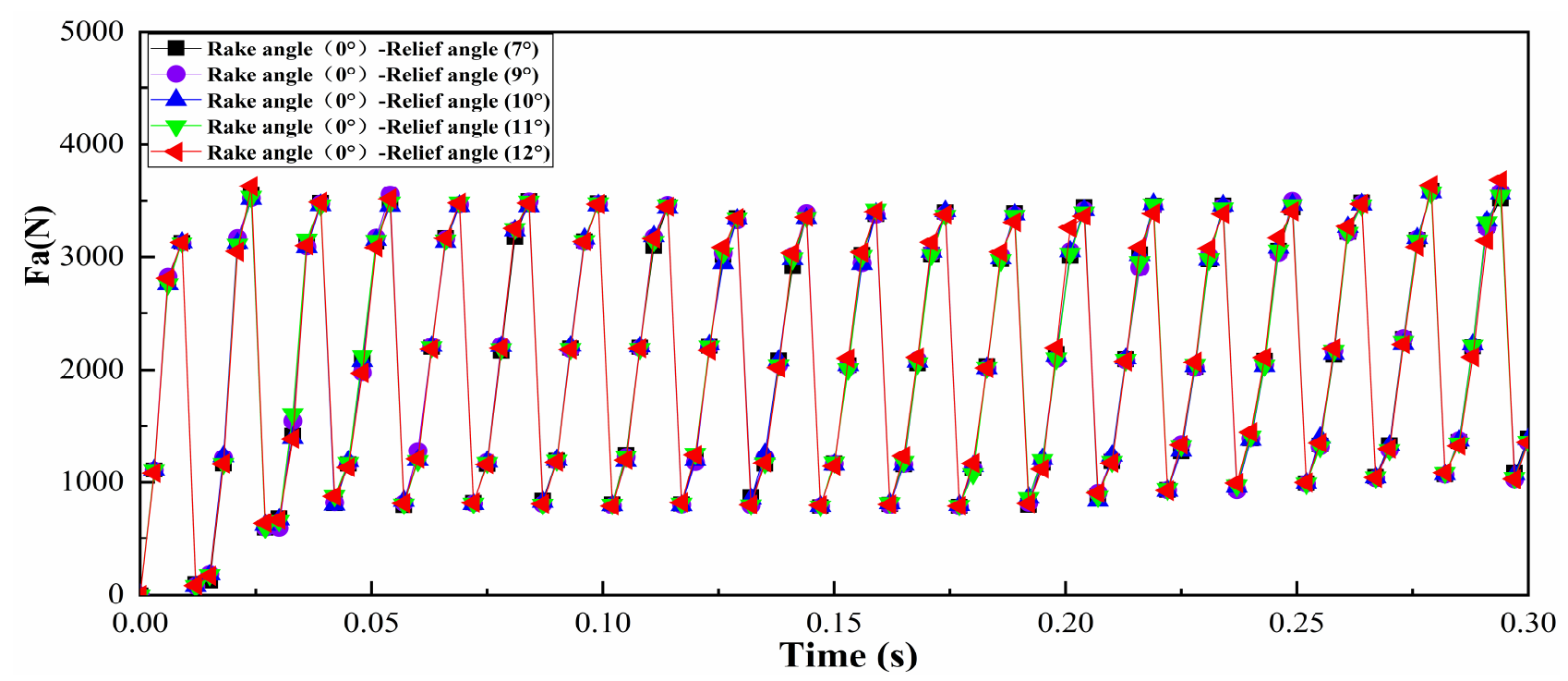

(d) The influence of relief angle of the blade on axial force

Fig. 8 Variation law of axial force with time

Figure 8 shows the variation law of axial force with time. It can be seen from Fig. 8(a) and Fig. 8(b) that when the rotation speed, feed rate, and rake angle remain unchanged, the axial force on the tool gradually decreases with the decrease of the rake angle. When the rake angle is $2^{\circ}$, the axial force value is the maximum, and when the rake angle is $-10^{\circ}$, the axial force value is the minimum. The amplitude of the axial force between the two can differ by $2000 \mathrm{~N}$. It is clear that the axial force on the tool can be reduced by increasing the negative rake angle appropriately. Fig. 8(b) shows the influence of the rake angle on the axial force when the relief angle is $8^{\circ}$, and the variation of the axial force is consistent with Fig. 8(a). This fully shows that the selection of appropriate rake angles can reduce the axial force on the tool and improve the force situation on the tool. It can be seen from Fig. 8(d) that when rotation speed, feed rate, and rake angle remain unchanged, the amplitude of axial force does not change obviously with the increase of the relief angle. It can be clearly seen that the rake angle has a more significant influence on the axial force than the relief angle.

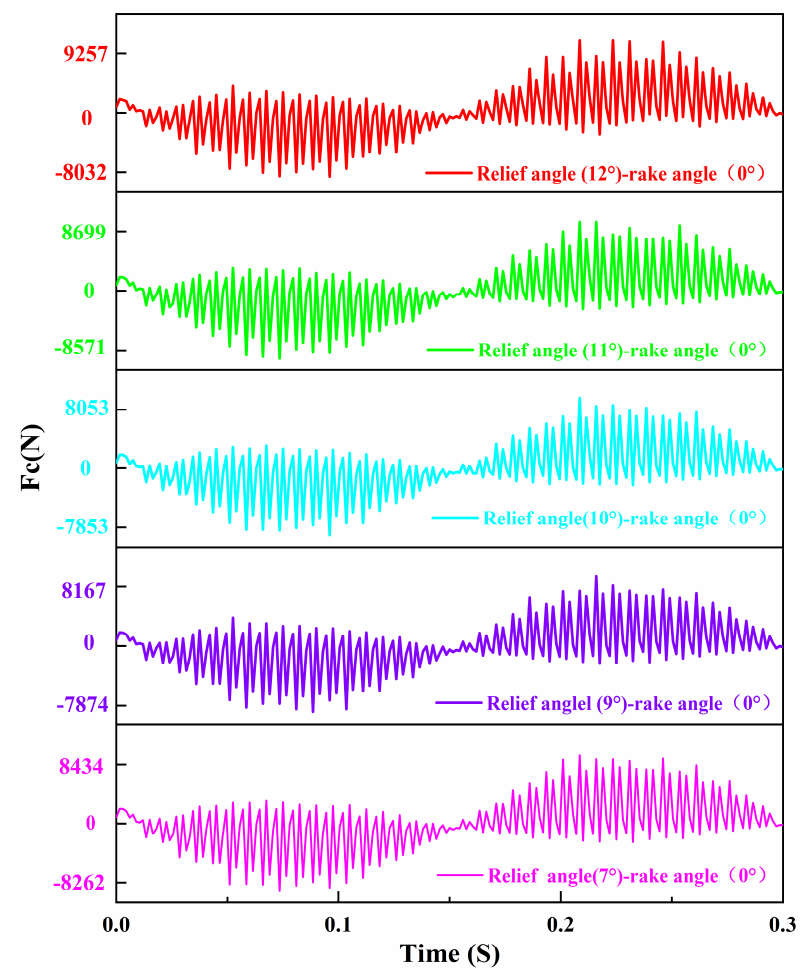

(a) The influence of relief angle on cutting force

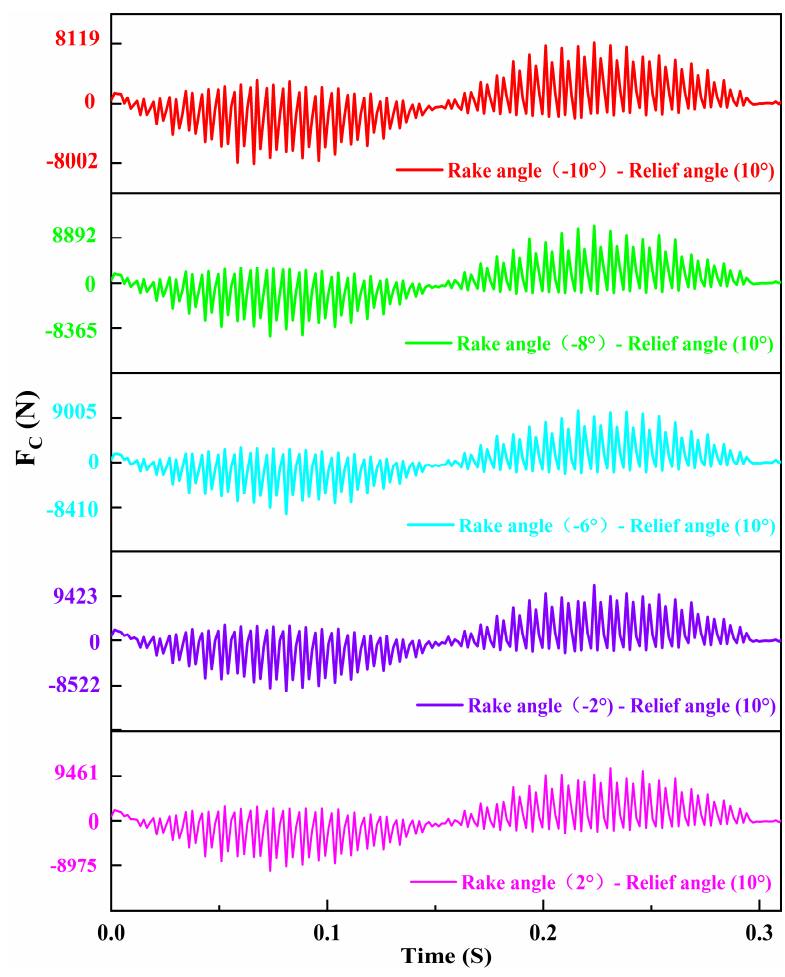

(b) The influence of rake angle on cutting force

Fig. 9 The variation law of cutting force $(\mathrm{Fc})$ with time. 
Figure 9 shows the variation law of cutting force $(\mathrm{Fc})$ with time. Furthermore, except for the change in the rake angle and relief angle of the tool, the rest of the tool angle remains unchanged and the tool structure parameters in Table 2 are still used, same machining process parameters as Fig. 8. It can be seen from Fig. 9(a) that when the rotation speed, feed rate, and rake angle remain unchanged, the maximum value of cutting force $\left(\mathrm{F}_{\mathrm{C}}\right)$ amplitude is different when the relief angle is different. With the increase of the relief angle, the maximum value of the cutting force $\left(\mathrm{F}_{\mathrm{C}}\right)$ amplitude generally shows an upward trend, and the cutting force amplitude is the largest when the relief angle is $12^{\circ}$. It can be seen from Fig. 9(b) that when the rotation speed, feed rate, and relief angle remain unchanged, the cutting force amplitude decreases with the decrease of the rake angle. Correspondingly, the reduction of the cutting force value $\left(\mathrm{F}_{\mathrm{C}}\right)$ also means that the smaller the erosion of the hole wall in the radial direction, the less significant the trend of the blade expanding from the inside to the outside in the radial direction of the deep hole. Therefore, it is recommended that the rake angle and relief angle should not be too large.

\section{Multi-objective optimization of parameters}

In this section, the prediction model of drilling force is established based on the response surface regression analysis method and the optimization objective function is established. The random direction search method is used to optimize the blade angle and process parameters. The optimal parameter matching for BTA deep hole drilling Inconel 718 is realized.

\subsection{Prediction model of drilling force}

The orthogonal experiment of deep hole machining with 5 factors and 6 levels was designed. The table of orthogonal factors is shown in Table 4. The finite element simulation software is used for calculation, and the values of cutting force $\left(\mathrm{F}_{\mathrm{C}}\right)$ and axial force $(\mathrm{Fa})$ are obtained under different parameters.

Table 4 Orthogonal factor table

\begin{tabular}{c|c|c|c|c|c|c}
\hline level & 1 & 2 & 3 & 4 & 5 & 6 \\
\hline Factor & 2 & 0 & -2 & -6 & -8 & -10 \\
\hline Rake angle $\left(^{\circ}\right)$ & 6 & 7 & 8 & 9 & 10 & 11 \\
\hline Relief angle $\left(^{\circ}\right)$ & 10 & 11 & 12 & 13 & 14 & 15 \\
\hline Center blade relief angle $\left(^{\circ}\right)$ & 140 & 160 & 180 & 200 & 220 & 240 \\
\hline Rotation speed $\left(\mathrm{r} \cdot(\mathrm{min})^{-1}\right)$ & 0.02 & 0.03 & 0.05 & 0.08 & 0.1 & 0.12 \\
\hline Feed rate $\left(\mathrm{mm} \cdot(\mathrm{r})^{-1}\right)$ & & & & & \\
\hline
\end{tabular}

The mathematical model of drilling force for BTA deep hole machining was established based on response surface regression analysis. The prediction model of drilling force is obtained as follows:

$$
\begin{aligned}
& \mathrm{F}_{\mathrm{a}}=3218+30.75 \beta_{1}-14.14 n+23204 f-330 \beta_{2}+169 \beta_{3}-1.15 \beta_{1}^{2}+0.044 n^{2} \\
& -12164 f^{2}+17.7 \beta_{2}{ }^{2}-6.16 \beta_{3}{ }^{2} \\
& \mathrm{~F}_{\mathrm{c}}=3445+123 \beta_{1}+60.6 n+188 f+763 \beta_{2}-478 \beta_{3}+1.01 \beta_{1}^{2}-0.1399 n^{2} \\
& +84089 f^{2}-42.4 \beta_{2}{ }^{2}+19.5 \beta_{3}{ }^{2}
\end{aligned}
$$

Where: $\beta_{1}$ - rake angle of the blade; $\beta_{2}$ - relief angle of the outer blade and intermediate blade; $\beta_{3}$ - relief angle of the center blade.

\subsection{Objective function}

Material removal rate (MMR) is an important index of drilling. The greater the material removal amount, the higher the efficiency of deep hole machining. According to the definition of drilling, MMR is calculated by feed rate and rotation speed (Araujo et al., 2013). MMR can be expressed as: 


$$
M M R=\frac{n f}{60} \cdot \pi \cdot\left(K_{1} L_{1}+K_{2} L_{2}+K_{3} L_{3}\right)
$$

where: $L_{1}$ - length of the outer blade; $L_{2}$ - length of the intermediate blade; $L_{3}$ - length of the center blade; $n$-rotation speed; $f$-feed rate; $K_{1}$ - the sum of the distance between the two ends of the outer blade and the center axis of the hole; $K_{2}$ - the sum of the distance between the two ends of the intermediate blade and the center axis of the hole; $K_{3}$ - the radius of the cone formed by the center blade about the central axis of the hole.

Substituting the drilling parameters and tool parameters into Eq. (12), the function expression is expressed as:

$$
M M R=55.72 n f
$$

To sum up, the objective function of the optimization model is as follows :

$$
\left\{\begin{array}{l}
\mathrm{F}_{\mathrm{C}}\left(x_{1}, x_{2}, x_{3}, x_{4}, x_{5}\right) \\
\mathrm{Fa}\left(x_{1}, x_{2}, x_{3}, x_{4}, x_{5}\right) \\
\operatorname{MMR}\left(x_{1}, x_{2}, x_{3}, x_{4}, x_{5}\right)
\end{array}\right.
$$

\subsection{Constraints and optimization results}

It can be seen from the field experiment that when the rotation speed is $300 \mathrm{rev} / \mathrm{min}$ and the feed rate is $0.08 \mathrm{~mm} / \mathrm{r}$, the tool wears severely and the outer edge of the outer blade (position 1 in Fig.7) breaks. when the rotation speed is 240 $\mathrm{rev} / \mathrm{min}$ and the feed rate is $0.05 \mathrm{~mm} / \mathrm{r}$, the tool does not break. Therefore, the axial force and cutting force under this condition are selected as constraint conditions. To ensure that the drilling force is reasonable, the greater the material removal and the smaller the drilling force. the mathematical software is used to program, and the random direction search method is used to solve the optimization model. The constraint condition established in this paper is Eq. (15), and the optimization results are shown in Table 5.

$$
\left\{\begin{array}{l}
140 r / \mathrm{min} \leq n \leq 240 \mathrm{r} / \mathrm{min} \\
0.01 \mathrm{~mm} / r \leq f \leq 0.05 \mathrm{~mm} / r \\
-10^{\circ} \leq \beta_{1} \leq 2^{\circ} \\
7^{\circ} \leq \beta_{2} \leq 12^{\circ} \\
10^{\circ} \leq \beta_{3} \leq 15^{\circ} \\
\mathrm{Fa} \leq 3122 N \\
\mathrm{~F}_{\mathrm{C}} \leq 10478 N
\end{array}\right.
$$

Table 5 Optimization Results

\begin{tabular}{c|c|c|c|c|c|c}
\hline $\begin{array}{c}n \\
\left(\mathrm{rev} \cdot \mathrm{min}^{-1}\right)\end{array}$ & $\begin{array}{c}f \\
\left(\mathrm{~mm} \cdot \mathrm{rev}^{-1}\right)\end{array}$ & $\begin{array}{c}\beta_{1} \\
\left({ }^{\circ}\right)\end{array}$ & $\begin{array}{c}\beta_{2} \\
\left({ }^{\circ}\right)\end{array}$ & $\begin{array}{c}\beta_{3} \\
\left({ }^{\circ}\right)\end{array}$ & $\begin{array}{c}\mathrm{F}_{\mathrm{C}} \\
(\mathrm{N})\end{array}$ & $\begin{array}{c}\mathrm{Fa} \\
(\mathrm{N})\end{array}$ \\
\hline 200 & 0.03 & -6 & 10 & 12 & 9811 & 2220 \\
\hline
\end{tabular}

\section{Experiment and results of drilling Inconel 718}

Based on the above research, deep hole drilling experiments were carried out with the optimized BTA tool and process parameters. The influence of different drilling process parameters on the straightness of the deep hole of nickelbased superalloy was studied. According to experiment results of the field deep hole drilling, it is judged whether the 
deep hole straightness of nickel-based superalloys can be improved by optimizing the tool structure and process parameters. CW6163D deep hole drilling machine (Fig. 10) and ultrasonic thickness gauge (Fig. 11) were used in the experiment. In the drilling experiment, the rotation speed and the feed rate were changed by the single factor experiment method. The coolant is SAE5W-30 oil, and the oil pressure adopts $1.5 \mathrm{Mpa}$.

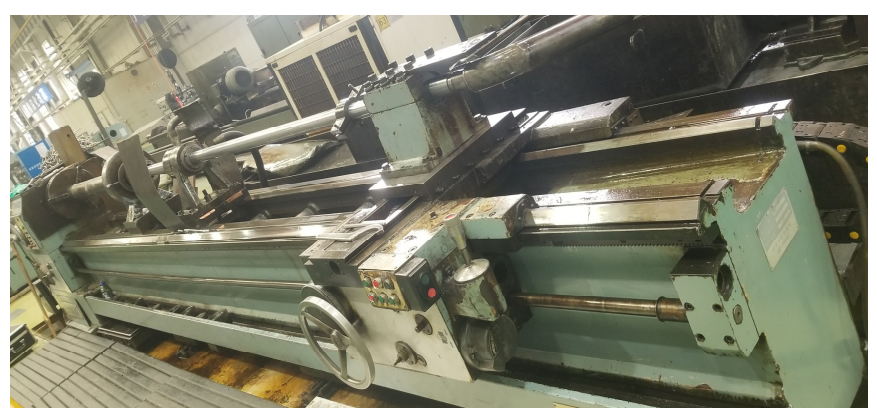

Fig. 10 Experimental setup

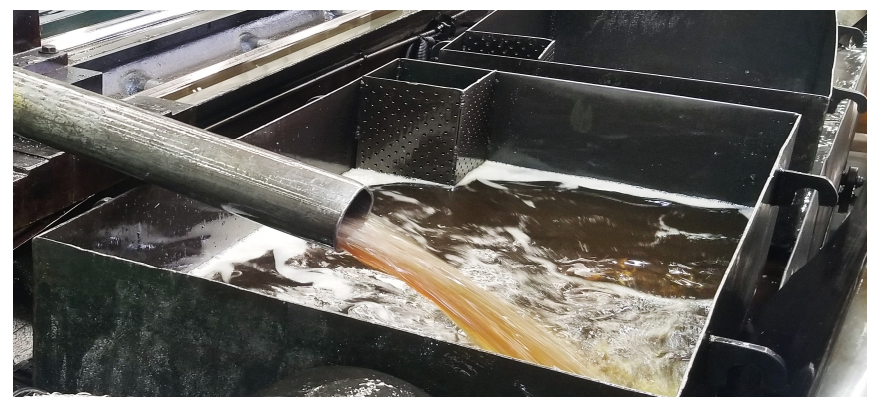

Fig. 12 Cooling oil

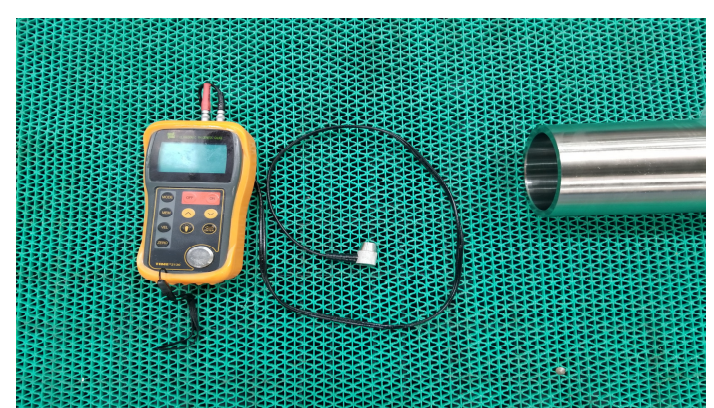

Fig. 11 Ultrasonic thickness gauge

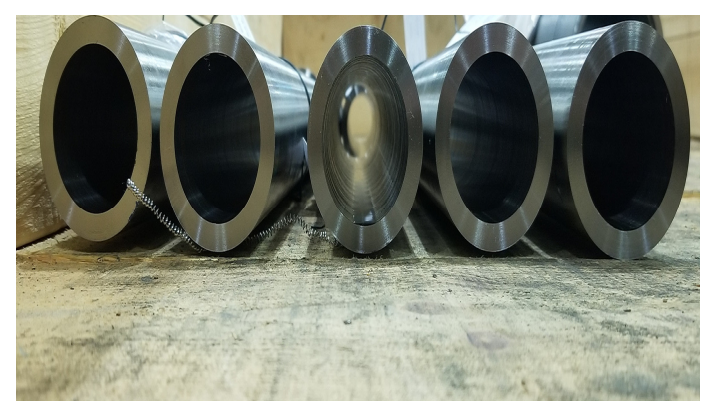

Fig. 13 Workpiece

Table 6 Main experimental results

\begin{tabular}{c|c|l}
\hline Rotation speed & Feed rate & \multicolumn{1}{|c}{ The main situation of the experiment } \\
\hline $140 \mathrm{rev} / \mathrm{min}$ & $0.03 \mathrm{~mm} / \mathrm{rev}$ & The straightness is good, the blade is slightly worn \\
\hline $140 \mathrm{rev} / \mathrm{min}$ & $0.1 \mathrm{~mm} / \mathrm{rev}$ & Blade wear significantly \\
\hline $180 \mathrm{rev} / \mathrm{min}$ & $0.03 \mathrm{~mm} / \mathrm{rev}$ & There are chattering lines on the inner surface of the hole \\
\hline $200 \mathrm{rev} / \mathrm{min}$ & $0.03 \mathrm{~mm} / \mathrm{rev}$ & The straightness is good, the blade is slightly worn \\
\hline $200 \mathrm{rev} / \mathrm{min}$ & $0.08 \mathrm{~mm} / \mathrm{rev}$ & The edge of the outer blade is severely worn, and the straightness is poor \\
\hline $240 \mathrm{rev} / \mathrm{min}$ & $0.03 \mathrm{~mm} / \mathrm{rev}$ & There are chattering lines on the inner surface of the hole \\
\hline $300 \mathrm{rev} / \mathrm{min}$ & $0.08 \mathrm{~mm} / \mathrm{rev}$ & The edge of the outer blade breaks \\
\hline
\end{tabular}

The main results of the field drilling experiment are shown in Table 6. It is known from the drilling test that the edge of the outer blade is easy to wear. The test results show that the drilling force is different under the conditions of different rotation speeds and feed rates. When the rotation speed and feed rate are too large, under the condition of high rotation speed (300 rev/min) and feed rate $(0.08 \mathrm{~mm} / \mathrm{rev})$, the edge of the outer blade (position 1 in Fig. 7) of the tool breaks, which means that the force on the edge of the outer blade is too large, exceeding the breaking strength of the outer blade. By studying the cutting force on the tool under different parameters and comparing with the field test results, it was found that the higher the cutting force, the higher the likelihood of break at the edge of outer blade, which is caused by a change in the magnitude of the force. The greater the cutting force, which means the stronger the interaction force between the outer blade and the hole wall. It also means that the tendency of the blade expanding from the inside to the outside in the radius direction of the deep hole is more pronounced. Different process parameters have different effects on the chattering phenomenon of the tool. 


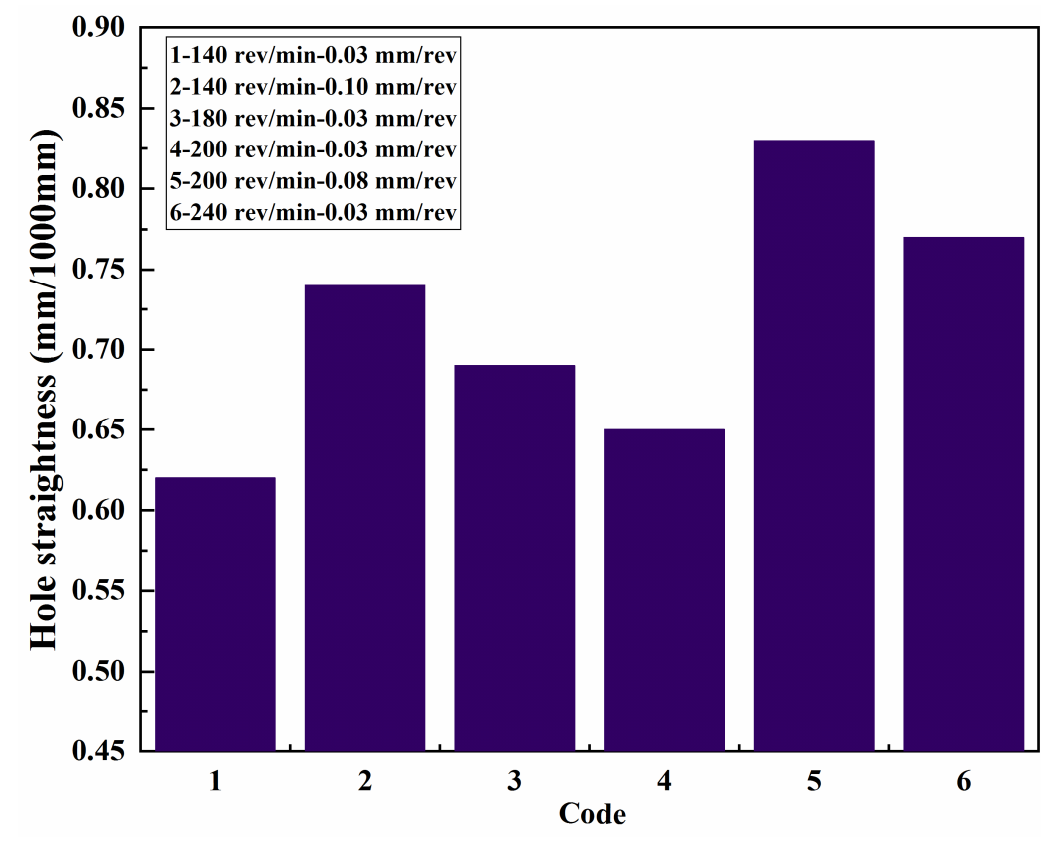

Fig. 14 The straightness of deep hole

Figure 14 shows the straightness data of the deep hole measured after the experiment. When the process parameters are $200 \mathrm{rev} / \mathrm{min}$ and $0.03 \mathrm{~mm} / \mathrm{rev}$, the deep hole straightness and processing efficiency are relatively good. It can be seen that different process parameters have different effects on the straightness of the deep hole, and the straightness of the deep hole can be improved by optimizing process parameters. According to the field production in the factory, the nonoptimized BTA tool is used for deep hole drilling Inconel718, and the straightness range of the deep hole is 0.76-1.14 $\mathrm{mm} / 1000 \mathrm{~mm}$. As can be seen from Fig. 14, the straightness range of the deep hole processed by the optimized BTA tool is $0.62-0.83 \mathrm{~mm} / 1000 \mathrm{~mm}$. This fully indicates that the straightness of the deep hole in nickel-based superalloys can be improved by optimizing the tool structure. The deviation of the hole axis is affected by many factors. It is possible to control the deviation of hole straightness by taking reasonable means.

\section{Conclusion}

In order to solve the problem of poor straightness of the deep hole in nickel-based superalloys, this paper establishes a three-dimensional finite element model of BTA deep hole drilling Inconel 718 based on thermal-mechanical coupling. On this basis, the multi-objective optimization of the tool structure and process parameters is carried out. The optimized BTA tool is used for deep hole drilling experiments, and the following conclusions are obtained:

(1) Different rotation speeds and feed rates will lead to different degrees of strain hardening and thermal softening. This will lead to a significant difference in the value of the drilling force on the tool. In order to avoid blade fracture, low rotation speed and low feed rate are recommended for process parameters.

(2) The higher the cutting force, the higher the possibility of break at the edge of the outer blade, which is caused by a change in the magnitude of the force. The greater the cutting force, which means the stronger the interaction between the outer blade and the hole wall. At the same time, it also means that the tendency of the blade expanding from the inside to the outside in the radius direction of the deep hole is more pronounced.

(3) In the process parameter selection of BTA deep hole drilling nickel-based superalloys, the recommended rotation speed of this article is $200 \mathrm{r} / \mathrm{min}$, the feed rate is $0.03 \mathrm{~mm} / \mathrm{r}$; in terms of selection of blade angle, the recommended rake angle of the blade is $-6^{\circ}$, relief angle of the outer blade and intermediate blade is $10^{\circ}$, and relief angle of the center blade is $12^{\circ}$. Different process parameters have different effects on the chatter phenomenon of the tool, which will affect the straightness of the deep hole.

(4) The straightness deviation of the deep hole in nickel-based superalloys can be controlled by optimizing the tool structure and process parameters. The research work in this paper can provide a basis for the structural design of the BTA tool and optimization of process parameters. 


\section{Acknowledgments}

This research was supported by Sichuan science and technology program (2019YFG0380, 2021ZHCG0013), China National Petroleum Corporation science and technology planning project "Gas well pressure operation technology popularization" (2020B-4121).

\section{References}

Ahmadi, K., and Altintas, Y., Stability of lateral, torsional and axial vibrations in drilling(Article), International Journal of Machine Tools and Manufacture, Vol.68 (2013), pp. 63-74.

Ahmed, A., Lew, M.T., Diwakar, P., Kumar, A.S., and Rahman, M., A novel approach in high performance deep hole drilling of Inconel 718, Precision Engineering, Vol.56 (2019), pp.432-437.

Araujo, A., Fromentin, G., and Poulachon, G., Analytical and experimental investigations on thread milling forces in titanium alloy, International Journal of Machine Tools and Manufacture, Vol.67 (2013), 28-34.

Attanasio, A., Ceretti, E., Outeiro, J., and Poulachon, G., Numerical simulation of tool wear in drilling Inconel 718 under flood and cryogenic cooling conditions, Wear, Vol.458-459 (2020), pp.203403.

Biermann, D., and Iovkov, I., Investigations on the thermal workpiece distortion in MQL deep hole drilling of an aluminium cast alloy, Cirp Annals-Manufacturing Technology, Vol.64, No.1 (2015), pp.85-88.

Furukawa, Y., and Moronuki, N., Effect of Material Properties on Ultra Precise Cutting Processes, CIRP Annals, Vol.37, No.1 (1988), pp.113-116.

Gerken, J.F., Klages, N., Biermann, D., and Denkena, B., In-process compensation of straightness deviation in BTA deep hole drilling using experimental and simulative analysis, Procedia CIRP, Vol. 93 (2020), pp.1417-1422.

Haddag, B., Nouari, M., and Moufki, A., Experimental analysis of the BTA deep drilling and a new analytical thermomechanical model for assessment of cutting forces and BTA drill design, International Journal of Advanced Manufacturing Technology, Vol.106, No.1-2 (2020), pp.455-469.

Hu, Z., Zhu, L., Wang, B., Liu, Z., Miao, Y., Xie, P., Gu, S., and Sheng, W., Computer simulation of the deep extrusion of a thin-walled cup using the thermo-mechanically coupled elasto-plastic FEM, Journal of Materials Processing Technology, Vol.102, No.1-3 (2000), pp.128-137.

Khadtare, A.N., Pawade, R.S., and Joshi, S., Surface integrity studies for straight and inclined hole in micro-drilling of thermal barrier coated Inconel 718: A turbine blade application, Precision Engineering, Vol.66 (2020), pp. 166-179.

Lew, M.T., Chaudhari, A., and Neo, W.K., Modeling of dynamic behavior of multispan gundrilling shaft with coolant and its effect on straightness deviation, CIRP Journal of Manufacturing Science and Technology, Vol.29 (2020), pp. 11-24.

Li, J., Tao, Z., Cai, X., An, Q., and Chen, M., Experimental and finite element analysis of the formation mechanism of serrated chips of nickel-based superalloy Inconel 718, The International Journal of Advanced Manufacturing Technology, Vol.107, No.11-12 (2020), pp.4969-4982.

Li, L., Xue, H., Li, D., and He, N., Effects of multi-support misalignments on hole straightness predict model in deep hole drilling, Journal of the Brazilian Society of Mechanical Sciences and Engineering, Vol. 42, No.5 (2020), pp.219.

Li, X., Zheng, J., Li, Y., Kong, L., Shi, W., and Guo, B., Modeling and distribution laws of drilling force for staggered teeth BTA deep hole drill, Mathematical Problems in Engineering, Vol.2018, pp.3691468.

Liu, Z., Liu, Y., Han, X., and Zheng, W., Study on super-long deep-hole drilling of titanium alloy, Journal of Applied Biomaterials and Functional Materials, Vol.16 (2018), pp.150-156.

Lu, X., Wang, H., Jia, Z., Feng, Y., and Liang, S., Coupled thermal and mechanical analyses of micro-milling Inconel 718, Proceedings of the Institution of Mechanical Engineers Part B - Journal of Engineering Manufacture, Vol.233, No.4 (2019), pp.1112-1126.

Ma, G., and Shen, X., Eigensolution of a BTA deep-hole drilling shaft system, Journal of Mechanical Science and Technology, Vol.32, No.4 (2018), pp.1499-1504.

Malarvizhi, S., Chaudhari, A., Woon, K.S., Kumar, A.S., and Rahman, M., Influence of burnishing axial interference on hole surface quality in deep hole drilling of Inconel 718, Procedia Manufacturing. Vol.5 (2016), pp.1295-1307.

Matsuzakia, K., Ryub, T., Sueokac, A., and Tsukamotod, K., Theoretical and experimental study on rifling mark generating phenomena in BTA deep hole drilling process (generating mechanism and countermeasure), International 
Journal of Machine Tools and Manufacture, Vol.88 (2015), pp.194-205.

Neo, D.W.K.a., Liu, K.a., and Kumar, A.S.b., High throughput deep-hole drilling of Inconel 718 using PCBN gun drill, Journal of Manufacturing Processes, Vol.57 (2020), pp.302-311.

Ohashi, T., Goto, R., Muto, K., and Yoshida, M., Mechanical properties of Inconel 718 nickel-Based superalloy around solidus temperature, Journal of the Japan Institute of Metals, Vol.76 (2012), pp.148-154.

Paturi, U.M.R., Methuku, S., Siripragada, S.S., Sangishetty, Y., and Gunda, R.K., Finite element simulations of machinability parameters in turning of Inconel 718, Materials Today: Proceedings, Vol.38, No.5 (2021), 2658-2663.

Uhlmann, E., Schulenburg, M.G.v.d., and Zettier, R., Finite element modeling and cutting simulation of Inconel 718, CIRP Annals - Manufacturing Technology, Vol.56, No.1 (2007), pp.61-64.

Woon, K.S., Chaudhari, A., Kumar, A.S., and Rahman, M., The effects of tool degradation on hole straightness in deep hole gundrilling of Inconel 718, Procedia CIRP, Vol.14 (2014), pp.593-598.

Woon, K.S., Chaudhari, A., Rahman, M., Wan, S., and Kumar, A.S., The effects of tool edge radius on drill deflection and hole misalignment in deep hole gundrilling of Inconel-718, CIRP Annals, Vol.63, No.1 (2014), pp.125-128.

Yu, L., Guo, C., Ranganath, S., Talarico, and R.A., Multi-phase FE model for machining Inconel 718, ASME 2010 International Manufacturing Science and Engineering Conference, (2010).

Zhang, X., Tnay, G., Liu, K., and Kumar, A., Effect of apex offset inconsistency on hole straightness deviation in deep hole gun drilling of Inconel 718, International Journal of Machine Tools and Manufacture, Vol.125 (2018), pp.123132. 